\title{
Research
}

\section{Trends in doctors' early career choices for general practice in the UK:}

\author{
longitudinal questionnaire surveys
}

\begin{abstract}
\section{Background}

The percentage of newly qualified doctors in the UK who want a career in general practice

declined substantially in the 1990s. The English Department of Health expects that half of all doctors will become GPs.
\end{abstract}

\section{Aim}

To report on choices for general practice made by doctors who qualified in 2000, 2002, 2005 . 2008 , and 2009

\section{Design and setting}

A structured, closed questionnaire about future career intentions, sent to all UK medical graduates.

\section{Method}

Questionnaires sent 1 year after qualification (all cohorts) and 3 years after lall except 2008 and 2009).

\section{Results}

Percentages of doctors who expressed an unreserved first choice for general practice in the first year after qualification, in the successive five cohorts, were $22.2 \%, 20.2 \%$, $23.2 \%, 21.3 \%$, and $20.4 \%$. Percentages who expressed any choice for general practice whether first, second or third - were $46.5 \%$, $43.4 \%, 52.6 \%, 49.5 \%$, and $49.9 \%$. Three years after qualification, an unreserved first choice was expressed, in successive cohorts, by $27.9 \%$, $26.1 \%$, and $35.1 \%$. Doctors from newly established English medical schools showed the highest levels of choice for general practice.

\section{Conclusion}

The percentage of doctors, in their first postqualification year, whose first choice of eventua career was general practice has not changed much in recent years. By year 3 after qualification, this preference has increased in recent years. At years 1 and 3 , the overall first choice for general practice is considerably lower than the required $50 \%$, but varies substantially by medical school. In depth studies of why this is so are needed.

\section{Keywords}

career choice; general practice; junior doctors: medical education; workforce planning.

\section{INTRODUCTION}

Recruitment of sufficient doctors to general practice is an issue of longstanding importance in medical workforce planning. In the UK, as elsewhere, ${ }^{1-4}$ there is concern that too few young doctors want careers in general practice. In a previous study it was reported that, in their first post-qualification year, $23 \%$ of UK graduates of 2002 wanted a career in general practice; ${ }^{5}$ but that GPs comprised $51 \%$ of the career grade workforce. ${ }^{5}$ The Department of Health in England currently intends that $50 \%$ of newly qualified doctors should be recruited to general practice to meet workforce requirements: "in future at least half of doctors going into specialty training will be training as GPs'. 6

Doctors' intended specialty choices, soon after graduation, are an early guide to their preferred career destinations, available before they apply for specialist training, and reflect doctors' aspirations developed during, and nurtured at, medical school.

The authors have surveyed UK medical graduates for many years. In the 1970s, over one-third of all newly-qualified doctors wanted careers in general practice, rising to $44 \%$ in 1983 , but falling to $20 \%$ in $1996 .^{7}$ The current study reports findings from the cohorts of 2000, 2002, 2005, 2008, and 2009.

\section{METHOD}

Questionnaires were sent to all UK medical graduates in selected qualification years 1 , 3 , and 5 years after graduation, and at longer time intervals after that. This study's

TW Lambert, MSc, statistician; MJ Goldacre FFPH, FRCP, professor of public health, UK Medical Careers Research Group, Department of Public Health, University of Oxford, Oxford.

\section{Address for correspondence}

Trevor Lambert, Unit of Health-Care

Epidemiology, Department of Public Health

University of Oxford, Rosemary Rue Building, Old Road Campus, Oxford, OX7 3LF. methods are described elsewhere.7,8 Several reminders were sent to nonresponders.

In each survey the authors sought to contact the whole cohort at the time of qualification. Addresses were obtained from doctors' registrations with the General Medical Council (GMC), and from responders themselves, and were regularly updated.

Doctors are asked to specify their career choice of specialty and to be as general or specific as you wish'. Doctors can, if they wish, list up to three choices of specialty in order of preference and can indicate choices of equal preference.

Standard summary statistics and confidence intervals ladjusted for finite populations) were used. Trends and significant differences were assessed using $\chi^{2}$ tests and McNemar's test for the significance of changes. ${ }^{9}$

This study reports percentages of men and women in each cohort who expressed a preference for a career in general practice. Historically more women than men have chosen general practice, and, in successive UK cohorts of doctors, there has been a rising proportion of women. Further, in these surveys, a higher percentage of women than men reply. Accordingly, percentages for each cohort are given that include adjustment for gender make-up (in practice, the unadjusted and adjusted figures differed by very little); and numbers scaled up from responder data to reflect the size of the whole cohort.
E-mail: trevor.lambertddph.ox.ac.uk Submitted: 7 April 2011; Editor's response: 4 May 2011; final acceptance: 3 June 2011. CBritish Journal of General Practice This is the full-length article (published online 27 Jun 2011) of an abridged version published in print. Cite this article as: Br J Gen Pract 2011; DOI: 10.3399/bjgp11X583173. 


\begin{abstract}
How this fits in
In the UK it is expected that about half of all newly qualified doctors will eventually become GPs. In the 1990s, the percentage of UK-trained doctors who, when they left medical school, wanted to become GPs was lower than that required to meet service needs. This study's data, from questionnaires sent to all qualifiers in the years 2000, 2002, 2005, 2008, and 2009. from all UK medical schools, shows that about $20-22 \%$ of doctors in their first postqualification year expressed a career preference for general practice as their unequivocal first choice of eventual career. There was no appreciable difference in this across the cohorts.
\end{abstract}

\section{RESULTS}

\section{Response}

Overall, of those for whom deliverable addresses were available, the response rate 1 year after qualification was 57\% (15103/26481 doctors); and 3 years after qualification it was 63\% (8425/13 311). Response varied across cohorts in year 1 from $69 \%$ of qualifiers of 2000 to $47 \%$ of those of 2009; and, in year 3, from $71 \%$ of qualifiers of 2000 to $56 \%$ of those of 2005 .

Untied first choices for general practice 1 year after graduation

An untied first choice is a first choice for general practice without the responder offering an equal first choice for another specialty. In the 2009 cohort, $20.4 \%$ of responders specified an untied first choice in 2010 for general practice $195 \%$ finite population confidence interval $[\mathrm{Cl}]=19.3 \%$ to $21.5 \%$ ). Equivalent percentages for the cohorts of 2000, 2002, 2005, and 2008 were, respectively, $22.2 \% \quad 195 \% \quad \mathrm{Cl}=21.3 \%$ to $23.1 \%$ ), $20.2 \%(95 \% \mathrm{Cl}=19.2 \%$ to $21.1 \%$ ), $23.2 \%(95 \% \mathrm{Cl}=22.3 \%$ to $24.1 \%)$, and $21.3 \%$ $195 \% \mathrm{Cl}=20.3 \%$ to $22.3 \%$ ). There was no trend over time (Table 1a; $\chi^{2}$ test for linear trend: $\chi^{2}{ }_{1}=1.2, P=0.28$ ).

Whole cohort estimates of the percentage choosing general practice, after adjusting for the higher percentage of women than men who responded to the surveys, were slightly lower at $21.6 \%, 19.5 \%, 22.6 \%$, $20.9 \%$, and $20.1 \%$, respectively, for the cohorts of 2000, 2002, 2005, 2008, and 2009.

\section{All first choices for general practice Iwhether or not shared with another specialtyl 1 year after graduation}

When those who chose general practice as their first choice jointly with another specialty ('tied first choices') were added (Table $1 \mathrm{~b}$ ), the percentages who chose general practice as a first choice, in the cohorts of 2000, 2002, 2005, 2008, and 2009 were, respectively, $29.6 \% 195 \% \mathrm{Cl}=28.7 \%$ to $30.6 \%$ ), $26.3 \%$ ( $95 \% \mathrm{Cl}=25.3 \%$ to $27.3 \%$ ), $33.0 \%(95 \% \mathrm{Cl}=31.9 \%$ to $34.0 \%), 31.0 \%$ (95\% $\mathrm{Cl}=29.9 \%$ to $32.1 \%$ ), and $30.6 \%$ (95\% $\mathrm{Cl}=29.3 \%$ to $31.8 \%$ ). Whole cohort estimates were slightly lower (Table 1b). There was evidence of a modest upward linear trend in all first choices for general practice $\left(\chi^{2}=5.9, P=0.015\right)$.

Table 1. Career preferences in the first year after qualification: percentage of responders in each graduation year who specified a career in general practice, and whole cohort estimates (see Method)

\begin{tabular}{|c|c|c|c|c|}
\hline \multicolumn{5}{|c|}{ Responders } \\
\hline Graduation year & Men \% (n/N) & Women $\%(n / N)$ & Total \% $(n / \mathrm{N})$ & Whole cohort estimate \\
\hline \multicolumn{5}{|c|}{ a) Untied first choices for general practice } \\
\hline 2009 & $15.4(154 / 998)$ & $22.9(440 / 1919)$ & $20.4(594 / 2917)$ & $20.1(1317)$ \\
\hline 2008 & $16.2(185 / 1140)$ & $24.0(519 / 2162)$ & $21.3(704 / 3302)$ & $20.9(1421)$ \\
\hline 2005 & $14.1(166 / 1181)$ & $28.8(560 / 1947)$ & $23.2(726 / 3128)$ & $22.6(1160)$ \\
\hline 2002 & $12.6(138 / 1091)$ & $25.0(422 / 1687)$ & $20.2(560 / 2778)$ & 19.5 (865) \\
\hline 2000 & $15.1(198 / 1307)$ & $27.7(463 / 1671)$ & $22.2(661 / 2978)$ & 21.6 (955) \\
\hline \multicolumn{5}{|c|}{ b) Tied and untied first choices for general practicea } \\
\hline 2009 & $23.5(235 / 998)$ & $34.2(657 / 1919)$ & 30.6 (892/2917) & 30.1 (1979) \\
\hline 2008 & $23.0(262 / 1140)$ & $35.2(762 / 2162)$ & $31.0(1024 / 3302)$ & $30.4(2063)$ \\
\hline 2005 & $22.2(262 / 1181)$ & $39.5(769 / 1947)$ & $33.0(1031 / 3128)$ & 32.3 (1655) \\
\hline 2002 & $17.2(188 / 1091)$ & $32.1(542 / 1687)$ & $26.3(730 / 2778)$ & $25.5(1131)$ \\
\hline 2000 & $20.4(267 / 1307)$ & $36.8(615 / 1671)$ & $29.6(882 / 2978)$ & $28.8(1275)$ \\
\hline \multicolumn{5}{|c|}{ c) Any choice for general practice ${ }^{b}$} \\
\hline 2009 & 40.0 (399/998) & $55.1(1058 / 1919)$ & $49.9(1457 / 2917)$ & 47.7 (3238) \\
\hline 2008 & $40.6(463 / 1140)$ & $54.3(1173 / 2162)$ & $49.5(1636 / 3302)$ & 49.0 (3326) \\
\hline 2005 & $41.0(484 / 1181)$ & $59.7(1162 / 1947)$ & $52.6(1646 / 3128)$ & $51.9(2661)$ \\
\hline 2002 & $32.0(349 / 1091)$ & $50.9(858 / 1687)$ & $43.4(1207 / 2778)$ & 42.5 (1883) \\
\hline 2000 & $36.0(470 / 1307)$ & $54.7(914 / 1671)$ & $46.5(1384 / 2978)$ & $45.5(2017)$ \\
\hline
\end{tabular}

alncludes all doctors who chose general practice as a first choice, whether or not combined with another specialty. ${ }^{b}$ ncludes all doctors who chose general practice, whether as first, second or third choice. 
Any choice for general practice 1 year after graduation

Table 1c shows the percentages in each graduation year that chose general practice, whether as first, second or third choice. In the 2008 and 2009 cohorts, approximately half the responders chose general practice: among graduates of 2008 the percentage was $49.5 \%(95 \% \mathrm{Cl}=48.3 \%$ to $50.8 \%$ ) and among graduates of 2009 it was $49.9 \%(1457 / 2917,95 \% \mathrm{Cl}=48.6 \%$ to $51.3 \%$ ). In the cohorts of 2000, 2002, and
2005 the corresponding percentages were $46.5 \%(95 \% \mathrm{Cl}=45.4 \%$ to $47.5 \%), 43.4 \%$ $(95 \% \mathrm{Cl}=42.3 \%$ to $44.6 \%)$, and $52.6 \%(95 \%$ $\mathrm{Cl}=51.5 \%$ to $53.7 \%$ ). Whole cohort estimates were slightly lower (Table 1c). The upward linear trend from 2000 to 2009 was significant $\left(\chi^{2_{1}}=19.0, P<0.001\right)$.

As Table 1 shows, the percentage of women who chose general practice was considerably, and consistently, higher than that of men.

\section{Table 2. Career preferences 1 year after graduation: percentages (numbers) of graduates who specified general practice as their choice of future career, grouped by clinical medical school attended}

\begin{tabular}{|c|c|c|c|c|}
\hline Medical school & $\begin{array}{l}\text { Untied first } \\
\text { choice for GP \% (n) }\end{array}$ & $\begin{array}{l}\text { Any first } \\
\text { choice for GP } \%(n)\end{array}$ & $\begin{array}{l}\text { Any choice } \\
\text { for GP } \%(n)\end{array}$ & Total N \\
\hline \multicolumn{5}{|l|}{ England } \\
\hline \multicolumn{5}{|l|}{ Oxford and Cambridge } \\
\hline Cambridge & $13.0(56)$ & $21.1(91)$ & $34.5(149)$ & 432 \\
\hline Oxford & $10.9(46)$ & $17.7(75)$ & $36.2(153)$ & 423 \\
\hline Total Oxford and Cambridge & $11.9(102)$ & $19.4(166)$ & 35.3 (302) & 855 \\
\hline \multicolumn{5}{|l|}{ London } \\
\hline Imperial College & $18.1(140)$ & $23.3(180)$ & $41.3(320)$ & 774 \\
\hline King's College & $17.5(167)$ & $24.9(237)$ & $44.9(427)$ & 952 \\
\hline Queen Mary and Westfield & $22.2(123)$ & $30.8(171)$ & $49.0(272)$ & 555 \\
\hline St George's & $21.0(110)$ & 30.3 (159) & $48.9(256)$ & 524 \\
\hline University College & $19.8(173)$ & $26.1(228)$ & 45.0 (393) & 874 \\
\hline Total London & 19.4 (713) & 26.5 (975) & 45.3 (1668) & 3679 \\
\hline \multicolumn{5}{|l|}{ Other English schools } \\
\hline Birmingham & $25.5(198)$ & $34.3(266)$ & $55.2(428)$ & 776 \\
\hline Bristol & $18.0(95)$ & $27.3(144)$ & $45.6(241)$ & 528 \\
\hline Leeds & $27.8(166)$ & $\mathbf{3 7 . 6}(225)$ & $56.0(335)$ & 598 \\
\hline Liverpool & $26.0(139)$ & 36.1 (193) & $53.6(287)$ & 535 \\
\hline Manchester & 22.3 (219) & 30.5 (300) & 50.6 (498) & 984 \\
\hline Newcastle & $22.6(149)$ & $31.6(208)$ & 50.9 (335) & 658 \\
\hline Sheffield & $24.1(162)$ & $33.6(226)$ & 50.4 (339) & 673 \\
\hline Nottingham & $22.2(144)$ & 31.2 (203) & 48.9 (318) & 650 \\
\hline Southampton & $24.3(121)$ & 33.1 (165) & 51.6 (257) & 498 \\
\hline Leicester & 20.9 (107) & $29.7(152)$ & 47.9 (245) & 512 \\
\hline Total other English & 23.3 (1500) & 32.5 (2082) & 51.2 (3283) & 6412 \\
\hline \multicolumn{5}{|l|}{ New English schools } \\
\hline Peninsula & 31.4 (37) & $40.7(48)$ & $55.9(66)$ & 118 \\
\hline Brighton and Sussex & $29.0(31)$ & 35.5 (38) & $57.9(62)$ & 107 \\
\hline Hull York & $30.4(34)$ & $43.8(49)$ & $65.2(73)$ & 112 \\
\hline East Anglia & $19.1(17)$ & 34.8 (31) & $61.8(55)$ & 89 \\
\hline Warwick & $27.1(56)$ & $\mathbf{4 3 . 0}(89)$ & $64.3(133)$ & 207 \\
\hline Total new English & $27.6(175)$ & $40.3(255)$ & 61.5 (389) & 633 \\
\hline Total England & $21.5(2490)$ & $30.0(3478)$ & $48.7(5642)$ & 11579 \\
\hline \multicolumn{5}{|l|}{ Scotland } \\
\hline Aberdeen & $24.0(114)$ & 33.5 (159) & $50.9(242)$ & 475 \\
\hline Dundee & $27.0(111)$ & $34.8(143)$ & $51.1(210)$ & 411 \\
\hline Edinburgh & $14.9(107)$ & $23.2(167)$ & $39.2(282)$ & 719 \\
\hline Glasgow & $18.9(122)$ & $28.6(184)$ & $46.1(297)$ & 644 \\
\hline Total Scotland & $20.3(457)$ & $29.0(653)$ & 45.8 (1031) & 2249 \\
\hline Wales (Cardiff) & $23.5(166)$ & $33.9(240)$ & $55.6(393)$ & 707 \\
\hline Northern Ireland (Belfast) & $23.7(128)$ & $33.5(181)$ & $47.5(257)$ & 541 \\
\hline Total & $21.5(3238)$ & $30.2(4552)$ & 48.6 (7323) & 15076 \\
\hline \multicolumn{5}{|c|}{ In each column, the overall $\chi^{2}$ test for significant differences by medical school was significant at $P<0.001$. } \\
\hline \multicolumn{5}{|c|}{ Percentages which are higher or lower than the overall average $(\mathbb{P}<0.01)$, based on analysis of adjusted } \\
\hline \multicolumn{5}{|c|}{$\begin{array}{l}\text { standardised residuals, are marked bold in each column. Excludes } 27 \text { doctors who replied in year } 1 \text { but whose } \\
\text { medical school was unknown. }\end{array}$} \\
\hline
\end{tabular}


Table 3. Career preferences in the third year after qualification: percentage of responders in each graduation year who specified a career in general practice, and whole cohort estimates (see Method)

\begin{tabular}{|c|c|c|c|c|}
\hline \multirow[b]{2}{*}{ Graduation year } & \multicolumn{3}{|c|}{ Responders } & \multirow[b]{2}{*}{ Whole cohort estimate } \\
\hline & Men $\%(n / N)$ & Women \% (n/N) & Total $\%(n / N)$ & \\
\hline \multicolumn{5}{|c|}{ a) Untied first choices for general practice } \\
\hline 2005 & $25.9(261 / 1009)$ & $40.6(691 / 1700)$ & $35.1(952 / 2709)$ & 34.5 (1768) \\
\hline 2002 & $16.7(177 / 1063)$ & $32.0(539 / 1685)$ & $26.1(716 / 2748)$ & $25.2(1116)$ \\
\hline 2000 & $20.1(268 / 1333)$ & $34.3(561 / 1635)$ & $27.9(829 / 2968)$ & $27.3(1212)$ \\
\hline \multicolumn{5}{|c|}{ b) Tied and untied first choices for general practice ${ }^{a}$} \\
\hline 2005 & $29.0(293 / 1009)$ & $43.8(745 / 1700)$ & $38.3(1038 / 2709)$ & $37.6(1931)$ \\
\hline 2002 & $19.7(209 / 1063)$ & $36.4(613 / 1685)$ & $29.9(822 / 2748)$ & 28.9 (1283) \\
\hline 2000 & $21.7(289 / 1333)$ & $38.2(624 / 1635)$ & $30.8(913 / 2968)$ & 30.1 (1333) \\
\hline \multicolumn{5}{|c|}{ c) Any choice for general practice ${ }^{b}$} \\
\hline 2005 & $35.0(353 / 1009)$ & $50.4(856 / 1700)$ & $44.6(1209 / 2709)$ & 43.9 (2253) \\
\hline 2002 & 30.7 (326/1063) & $47.7(803 / 1685)$ & $41.1(1129 / 2748)$ & 40.1 (1778) \\
\hline 2000 & $31.4(418 / 1333)$ & $51.1(836 / 1635)$ & $42.3(1254 / 2968)$ & $41.4(1836)$ \\
\hline
\end{tabular}

alncludes all doctors who chose GP as a first choice, whether or not combined with another specialty. bIncludes all doctors who chose GP, whether as first, second or third choice.

Variation by clinical medical school attended

When cohorts were combined and responders grouped by medical school attended, large differences by medical school were evident in the level of choices for general practice 1 year after graduation (Table 2). The highest rates of choice for general practice were found in most of the newly established English medical schools, and the lowest rates among graduates of Oxford and Cambridge. Schools whose levels of choice for general practice were higher or lower than the overall average are highlighted in Table 2.

\section{Variation by graduate entry}

Untied first choices for general practice were made by $23.5 \%$ (382/1628) of graduate entrants in the 2005, 2008, and 2009 cohorts, compared with $19.5 \%(1407 / 7220)$ of nongraduate entrants $\left(\chi_{1}^{2}=12.8, P<0.001\right)$. The percentages of graduate entrants and nongraduate entrants making any first choice for general practice (that is, including choices tied with another choicel were $34.9 \%$ (568/1628) and 28.7\% (2075/7220) respectively $\left(\chi^{2}{ }_{1}=23.7, \quad P<0.001\right)$; the percentages making any choice for general practice lwhether first, second or third choice) were $52.0 \%(846 / 1628)$ and $47.6 \%$ (3438/7220) respectively $\left(\chi^{2}{ }_{1}=9.9, P=0.002\right)$.

\section{Choices 3 years after graduation}

The percentages of responders who chose general practice as an untied first choice 3 years after graduation (Table 3a) were $27.9 \%, 26.1 \%$, and $35.1 \%$ in the cohorts of 2000, 2002, and 2005 respectively, a substantial increase between years 1 and 3 in each cohort. The percentages for all first choices, whether tied or untied, were also higher in year 3 than in year 1 (Table 3b). By contrast, considering all choices for general practice lwhether first, second or third choices), year 3 figures were lower than in year 1 (Table 3c).

Changes of choice between years 1 and 3 Changes of choice were examined for doctors who responded in both years 1 and 3 (Table 4). Of those who chose general practice as an untied first choice in year 1 , $82 \%$ did so again in year 3 . Women were a little more likely than men to do so. Fifteen per cent of doctors who did not choose general practice in year 1 did so in year 3.

In all, 773 responders chose general practice in year 3 but not year 1, while 271 chose general practice in year 1 but not year 3 . The percentage who chose general practice increased from $22.4 \%(1531 / 6820)$ in year 1 to $29.8 \%(2033 / 6820)$ in year 3 (McNemar's test, $P<0.001$ ). The net change represented $7.4 \%$ (502/6820) of responders, and meant that $38.0 \%$ (773/2033) of those who made a first choice for general practice in year 3 turned to it between years 1 and 3 .

Women were a little more likely than men to switch to general practice between years 1 and 3 .

Table 5 shows numbers who chose general practice as a first, second or third choice of specialty. For first, second or third choices combined, between years 1 and 3 , there were net reductions, both for men and women, in the total numbers who chose general practice (all $P<0.001$ ). For example, in year 13315 doctors gave a choice - first, second or third - for general practice. In year 3, the number had fallen to $2941 ; 946$ doctors who considered general practice in 


\section{Table 4. Untied first choices for general practice: changes of choice between the first and third post-graduate years (cohorts of 2000, 2002, and 2005, combined)}

\begin{tabular}{lccc} 
& \multicolumn{3}{c}{ Third year choice } \\
\cline { 2 - 4 } & GP & Not GP & Total \\
\hline a) Combined & & & \\
\hline First year choice & & & \\
GP & 1260 & 271 & 1531 \\
Not GP & 773 & 4516 & 5289 \\
Total & 2033 & 4787 & 6820 \\
\hline b) Men & & & \\
\hline First year choice & & & \\
GP & 300 & 79 & 379 \\
Not GP & 234 & 2022 & 2256 \\
Total & 534 & 2101 & 2635 \\
\hline c) Women & & & \\
\hline First year choice & & & \\
GP & 960 & 192 & 1152 \\
Not GP & 539 & 2494 & 3033 \\
Total & 1499 & 2686 & 4185 \\
\hline & & &
\end{tabular}

year 1 were no longer considering it, and 572 doctors were now considering general practice who had not considered it in year 1 (Table 5).

\section{DISCUSSION}

\section{Summary}

About one-fifth of UK graduates choose general practice as their sole first choice of career 1 year after graduation. This study's

\section{Table 5. Any choice for general practice: changes of choice between the first and third post-graduate years (cohorts of 2000, 2002, and 2005, combined)}

\begin{tabular}{lccc} 
& \multicolumn{3}{c}{ Third year choice } \\
\cline { 2 - 4 } & GP & Not GP & Total \\
\hline a) Combined & & & \\
\hline First year choice & & & \\
GP & 2369 & 946 & 3315 \\
Not GP & 572 & 2933 & 3505 \\
Total & 2941 & 3879 & 6820 \\
\hline b) Men & & & \\
\hline First year choice & & & \\
GP & 624 & 346 & 970 \\
Not GP & 215 & 1450 & 1665 \\
Total & 839 & 1796 & 2635 \\
\hline c) Women & & & \\
\hline First year choice & & & \\
GP & 1745 & 600 & 2345 \\
$\quad$ Not GP & 357 & 1483 & 1840 \\
Total & 2102 & 2083 & 4185 \\
\hline & & &
\end{tabular}

data show that this fraction has remained largely static across the past decade. If second and third choices are included, the figure rises to approximately a half in the most recent two cohorts of 2008 and 2009 studied in 2009 and 2010, in line, at first sight, with current UK policy targets. However, many doctors choosing general practice as a second or third choice in their first postgraduate year will eventually train in their first choice of another specialty rather than in general practice.

Data 3 years after graduation for the 2000, 2002, and 2005 cohorts give further insights. The cohort estimate of $34.3 \%$ of 2005 graduates who regard general practice as their sole first choice after 3 years is indicative of the percentage which may be expected to embark upon specialist training in general practice at that stage; many more than the $22.6 \%$ expressing the same intention in year 1 . Some of the rise no doubt reflects increasing acceptance of the likely availability of training and career grade posts in general practice compared with opportunities in other specialties. For others, change of choice towards general practice no doubt follows favourable changes in views about the desirability of a career in general practice. In the same span of time, between years 1 and 3 , the total percentage of the 2005 qualifying year who chose general practice fell to $43.9 \%$, compared with $51.9 \%$ who had expressed an interest in general practice at year 1, indicating a softening of initial choices for general practice which were uncertain. At least a partial explanation for this decline will be that doctors, originally content to enter general practice but preferring another specialty, will in fact have been on track for a career in the other specialty.

There was continued evidence of substantial differences in the level of choices for general practice among graduates of different medical schools, in line with the authors' previous study of the graduates of 1999 and 2000. ${ }^{10}$ Doctors from new medical schools in England showed a higher level of choices for general practice than doctors from other schools.

Graduate entrants were slightly more likely than non-graduate entrants to choose careers in general practice, as in earlier cohorts. ${ }^{11}$ However, to date, doctors have not been asked whether they undertook a specific fast-track graduate entry course; many of these courses are recently established and it is perhaps too soon to tell to what extent they will affect career choices among their graduates. 


\section{Strengths and limitations}

Strengths are that the study is large-scale lover 15000 responders in year 1), includes all UK medical schools, covers five cohorts of newly qualified doctors, and its longitudinal design means that each doctor's replies can be compared in years 1 and 3. Its main weakness is that some level of non-response is inevitable and the possibility of responder bias must be considered. Non-response varied between cohorts; but, in year 1 first choices (that is, the firmest early decision), the percentage who chose general practice was stable. This suggests that trends in non-responder bias are unlikely. Choices for general practice of doctors who responded to the first two mailings were compared with those who responded to subsequent mailings. Late responders were used as a proxy for non-responders (because the latter would have been non-responders, if the study had been confined to two mailings). The percentages who chose general practice were very similar in the two groups.

\section{Comparison with existing literature and implications for future research}

Year 1 results for the cohorts of 2008 and 2009 were broadly similar to results in earlier cohorts. It seems likely that the 2008 and 2009 cohorts will therefore have similar aspirations at year 3 as those in earlier cohorts. This suggests that the 50\% target, for recruiting to general practice, is a long way off the actual aspirations of doctors when they leave medical school.

The English Centre for Workforce Intelligence, reporting to the Department of Health on recommendations for medical specialty training for 2011, specifies that 2800 doctors were accepted for GP training in 2010 and recommends '... that moderate expansion is allowed from the existing GP training posts numbers for 2011 towards 3000 trainees. ${ }^{12}$ This number would represent $46 \%$ of the registered UK medical graduates of 2009.

Data from the 2008 and 2009 cohorts provide some evidence that the higher level of preference for general practice expressed by women than men, in the first year after qualification, is falling. If the gender gap is truly in decline, it may not be possible to rely for much longer on the 'demographic uplift' of an increasing percentage of women among the graduates resulting in more choosing general practice.

Information about early career preferences matters because early choices for general practice are highly predictive of eventual careers. For example, in previous cohorts $82 \%$ of doctors who specified that they wanted to become GPs in year 1, and $92 \%$ who specified this in year 3 , eventually practised as GPs. ${ }^{13}$

Extrapolating from the responder data to whole cohorts, and expressing the findings as numbers rather than percentages, the total number of young doctors choosing general practice 1 year after graduation, whether as first, second or third choice, has increased substantially since the year 2000 . This is due partly to the expansion of medical schools, and partly to increased numbers of women in medicine, rather than any substantial change in the underlying level of choice for general practice by either sex.

The doctors in previous cohorts regard general practice highly. ${ }^{14,15}$ Nonetheless, a much smaller percentage of doctors leave medical school wanting a career in general practice than the NHS needs. In this context the high level of choices for general practice among the first graduates from the new English schools is interesting.

This mirrors experience in the US, where the American Academy of Family Physicians has recently reported ${ }^{16}$ just a very small increase in interest in primary care careers among trainees in 2010, citing the following factors 'Multiple forces including student perspectives of the demands, rewards, and prestige of the specialty; national dialogue about health care reform; turbulence in the economic environment; lifestyle issues; the advice of deans; and the impact of faculty role models continue to influence medical student career choices.' Its report'16 continues 'Despite matching the highest number of US seniors into family medicine residencies since 2004, in 2010 the production of family physicians remains insufficient to meet the current and anticipated need to support the nation's primary care infrastructure.

In depth study of why this is so in the UK, and consideration of policy changes to encourage more doctors to enthusiastically embrace general practice as their first career choice, is required. Such study might consider the extent to which the level of choices for general practice in different schools reflects the different entry characteristics and aspirations of students, or whether it reflects the degree to which intentions are moulded by undergraduate experiences. this article on the Discussion Forum: http://www.rcgp.org.uk/bjgp-discuss 


\section{REFERENCES}

1. Koikea S, Matsumotoa S, Kodamab T, et al. Specialty choice and physicians career paths in Japan: an analysis of National Physician Survey data from 1996 to 2006. Health Policy 2010; 98(2-3): 236-244.

2. Buddeberg-Fischer B, Klaghofer R, Stamm M, et al. Primary care in Switzerland - no longer attractive for young physicians? Swiss Med Wkly 2006; 136(27-28): 416-424

3. López-Roig S, Pastor MA, Rodríguez C. The reputation and professional identity of family medicine practice according to medical students: a Spanish case study. Aten Primaria 2010; 42(12): 591-601.

4. Bethune C, Hansen PA, Deacon D, et al. Family medicine as a career option: how students' attitudes changed during medical school. Can Fam Physician 2007; 53(5): 881-885, 880 .

5. Lambert TW, Goldacre MJ, Turner G. Career choices of United Kingdom medical graduates of 2002: questionnaire survey. Med Educ 2006; 40(6): 514-521.

6. Department of Health. NHS next stage review: a high quality workforce. London: Department of Health 2008.

7. Lambert TW, Goldacre MJ, Edwards C, Parkhouse J. Career preferences of doctors who qualified in the United Kingdom in 1993 compared with those of doctors qualifying in 1974, 1977, 1980, and 1983. BMJ 1996; 313(7048): 19-24.

8. Goldacre MJ, Davidson JM, Lambert TW. Career choices at the end of the pre-registration year of doctors who qualified in the United Kingdom in 1996 Med Educ 1999; 33(12): 882-889.

9. Bland M. An introduction to medical statistics, 3rd ed. Oxford: Oxford University Press, 2000.

10. Goldacre MJ, Turner G, Lambert TW. Variation by medical school in career choices of UK graduates of 1999 and 2000. Med Educ 2004; 38(3): 249-258.

11. Goldacre MJ, Davidson JM, Lambert TW. Career preferences of graduate and non-graduate entrants to medical schools in the United Kingdom. Med Educ 2007; 41(4): 349-361.

12. Sharp P. Recommendation for specialty training 2011. London: Centre for Workforce Intelligence, 2010

13. Goldacre MJ, Laxton L, Lambert TW. Medical graduates' early career choices of specialty and their eventual specialty destinations: UK prospective cohort studies. BMJ 2010; 341: c3199.

14. Lambert TW, Evans J, Goldacre MJ. Recruitment of UK-trained doctors into general practice: findings from national cohort studies. Br J Gen Pract 2002; 52(478): 364-372

15. Lambert TW, Davidson JM, Evans J, Goldacre MJ. Doctors' reasons for rejecting initial choices of specialties as long-term careers. Med Educ 2003; 37(4): 312-318

16. Pugno PA, McGaha AL, Schmittling GT, et al. Results of the 2010 national resident matching program: family medicine. Fam Med 2010; 42(8): 552-561. 